\title{
Development of Effervescent-assisted Liquid Phase Microextraction using 1-dodecanol for Determination of Ketoprofen Drug in Water
}

\author{
Fatin Nur Izzati Mohd Fadzil, Saw Hong Loh, Marinah Mohd Ariffin \\ and Wan Mohd Afiq Wan Mohd Khalik* \\ Faculty of Science and Marine Environment, \\ Universiti Malaysia Terengganu, Terengganu, Malaysia
}

\begin{abstract}
A rapid and straightforward method based on effervescent-assisted dispersive liquid-liquid microextraction combined with high-performance liquid chromatography-ultraviolet (HPLC-UV) detection for preconcentration of ketoprofen in water samples was developed. The extraction efficiency of ketoprofen drug was investigated using $2^{3}$ central composite design. The values of optimum extraction condition were set as $300 \mu \mathrm{L}$ volume of 1-dodecanol, three pieces of tablets, and $30^{\circ} \mathrm{C}$ extraction temperature. The runtime was conducted in less than 6 min using a non-polar $\mathrm{C}_{18}$ column and an isocratic mobile phase (acetonitrile: water of 40:60 (v/v)) at a controlled flow rate of $1 \mathrm{~mL} \mathrm{~min}{ }^{-1}$. A good linear response was achieved in the range of $0.01-0.50 \mu \mathrm{g} \mathrm{mL} \mathrm{L}^{-1}\left(R^{2}>0.990\right)$. Detection and quantification limits were calculated at 0.001 and $0.004 \mu \mathrm{g} \mathrm{mL} \mathrm{L}^{-1}$, respectively. The average recoveries at three spiking concentration levels were within the range of $85 \%-108 \%$ with RSD $<10 \%(n=3)$. Real sample analysis was fortified using gel and standard solutions, and the calculated values were close to the actual values at $0.059 \mu \mathrm{g} \mathrm{mL} \mathrm{m}^{-1}$ (KET gel, initial concentration $0.075 \mu \mathrm{g} \mathrm{mL}^{-1}$ ) and $4.49 \mu \mathrm{g} \mathrm{mL}^{-1}$ (standard solution, initial concentration $5 \mu \mathrm{g} \mathrm{mL}^{-1}$ ), respectively.
\end{abstract}

Keywords: analgesic drug; central composite design; microextraction

\section{INTRODUCTION}

Ketoprofen (IUPAC name 2-(3-benzoylphenyl)propanoic acid), which is abbreviated as KET (Figure 1), belongs to non-steroidal anti-inflammatory drugs. KET has medicinal properties such as analgesic and antipyretic drugs. The pharmacological activity of KET is based on the inhibition of the COX-1 and COX-2 activity (Hatami \& Farhadi 2013).<smiles>CC(C(=O)O)c1cccc(C(=O)c2ccccc2)c1</smiles>

Figure 1. Formula structure of the molecule

Due to various KET applications in medicine, researchers find it challenging to develop a simple, sensitive, and low bias method for residual extraction or simultaneous determination on multiple matrices in which analyte always present at low concentration. Once consumed, 80\% of KET is eliminated as an uncharged drug, and its degradation in wastewater is subjected to biological treatment (Kermia et al., 2016). Different analytical methods, including solid phase extraction (Madikizela et al., 2014), solid-phase microextraction (Vera-Candioti et al., 2008), and liquid microextraction (Park \& Myung 2015), were applied for the determination of KET in environmental waters.

Sample preparation technique such as solid-phase extraction commonly used for preconcentration and cleaning up the drugs from different samples. This traditional technique put up to major limitations, including tiresome procedures, high cost, and high demand on large volumes of toxic organic solvents. Liquid phase microextraction offers new benefits such as minimal organic solvent usage, fast extraction, high accuracy, and precision. In advanced microextraction exploration, dispersive liquidliquid microextraction was first introduced by Rezaee et al. (2006). The working principle is based on the combination 
of an extraction solvent and a dispersion agent to form fine dispersion when the solvent comes into contact with the aqueous solution. The microextraction becomes a popular method due to its usefulness, simplicity, free energy, low consumption of organic solvents, high enrichment factor, and wide applications for analytes of different polarity (XiaoHuan et al., 2009; Zgoła-Grześkowiak \& Grześkowiak 2011).

Dispersion techniques are commonly accelerated using manual shaking, magnetic stirring, air, vortex, surfactant emulsion, ultrasound, microwave, or effervescent tablets (Leong et al., 2014). An effervescent tablet is a soluble tablet that involves acid-base reaction that produces carbon dioxide (CO2) bubbles, thus making it possible for fine dispersion of extraction solvent in an aqueous sample (Yıldız \& Çabuk 2018). This method is very rapid, effective, and reliable. Previous work indicated an effervescent tablet helps to improve extraction efficiency for the determination of herbicide (Liu et al., 2014) and fungicide (Jiang et al., 2014); however, the study on pharmaceutical drugs as model compounds is still limited.

In the present work, dispersive liquid-liquid microextraction (DLLME) with the acceleration of dispersion mode by effervescent tablets was utilised for the extraction of KET in the water samples. The influence of variables, such as the volume of extraction solvent, number of tablets, and the effect of temperature change was investigated and optimised using response surface methodology namely $2^{3}$ central composite design (CCD). The developed method was then validated using the Association of Official Analytical Chemist (AOAC) criteria to assess their performance.

\section{MATERIALS AND METHOD}

\section{A. Chemical and Reagents}

Ketoprofen standard (purity > 98\%) was purchased from Sigma-Aldrich (Steinheim, Germany). Methanol, acetonitrile (HPLC-grade), glycerine, 1-dodecanol (purity 99\%), sodium bicarbonate (purity 95\%), and sodium hydrogen phosphate (purity 95\%) were purchased from Merck (Darmstadt, Germany). Ketoprofen gel 2.5\% (Kop brand) was purchased from a local pharmacy. The stock solution of ketoprofen ( $5 \mu \mathrm{g}$ $\mathrm{mL}^{-1}$ ) was dissolved in methanol. The working solutions were prepared by appropriate dilution of the stock solution using deionised water produced by a Milli-Q system (Millipore, Bedford, MA, USA). All the standard solutions were stored at $4^{\circ} \mathrm{C}$ and brought to ambient temperature before use.

\section{B. Instrumentation}

The chromatographic separation was carried out with an HPLC system equipped with an autosampler (SIL-10ADVP), a vacuum degasser (DGU-14A), a system controller (SCL10AVP), a quaternary pump (LC-10ATVP), an oven (CTO10ASVP), a detector (SPD-10AVP), and an Apollo $\mathrm{C}_{18}$ column $(250 \mathrm{~mm} \times 4.6 \mathrm{~mm}, 5 \mu \mathrm{m})$. The final determination of ketoprofen was carried out at the optimum separation condition by HPLC with the isocratic binary mobile phase comprised 40:60 of acetonitrile: water. A flow rate set at $1 \mathrm{~mL}$ $\mathrm{min}^{-1}$. The run time was $6 \mathrm{~min}$, and the retention time of KET was integrated at $3.26 \mathrm{~min}$. The optimum wavelength was set up at $252 \mathrm{~nm}$. Injection volume per analysis was $20 \mu \mathrm{L}$.

\section{Preparation of Tablet}

In this study, the effervescent tablets were produced using the wet granulation method. Sodium bicarbonate (1 g) and sodium hydrogen phosphate $(1 \mathrm{~g})$ were weighed into a glass mortar, and sufficient ground to achieve homogenous mixing, and adopted as the effervescent precursors. The mixture was then transferred into a weighing boat with the dimension of $44 \mathrm{~mm} \times 44 \mathrm{~mm}$ and subsequently added with $1 \mathrm{~mL}$ glycerine (binder). The binder was used to enhance the tablet hardness to a level where handling is possible. Finally, the homogenous mixture was transferred into a tablet mould with the dimension of $2.5 \mathrm{~cm} \times 3.7 \mathrm{~cm}$ and subsequently compressed for $60 \mathrm{~s}$ to produce an effervescent tablet using a tablet press hammer. The effervescent tablets (internal diameter of 15 $\mathrm{mm}$, shown in Figure 2) were stored in a $30 \mathrm{~mL}$ plastic bottle with a screw cap at $4^{\circ} \mathrm{C}$ and brought to ambient temperature before use.

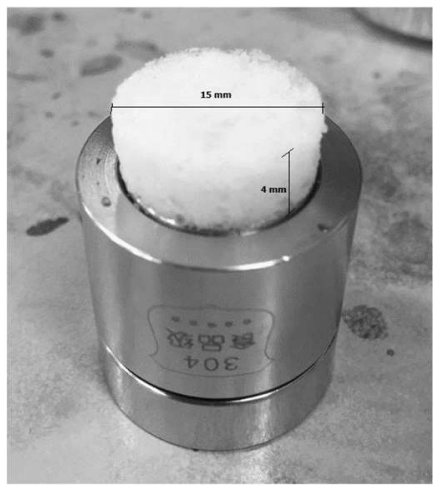

Figure 2. The dimension of the effervescent tablet 


\section{Extraction Procedure}

Deionised water $(80 \mathrm{~mL})$ was placed in a $100 \mathrm{~mL}$ beaker. Then, $\mathrm{X}_{1}$ of 1-dodecanol (as the extraction solvent) was added into the beaker. Next, the beaker was placed in a water bath positioned on a hot plate to control water temperature and investigate the effect of temperature change, $X_{3}$. Subsequently, the desired number of tablets, $\mathrm{X}_{2}$ was introduced into the solution for the extraction process. The generation of effervescent occurred from the bottom to the top of the beaker (Figure 3). Thus, it accelerated the KET movement towards the extractant solvent, which was positioned at the top of the solution. Once the effervescent reaction finished, the top portion of the solution (approximately $5 \mathrm{~mL}$ ) was taken and transferred to a $12 \mathrm{~mL}$ vial.

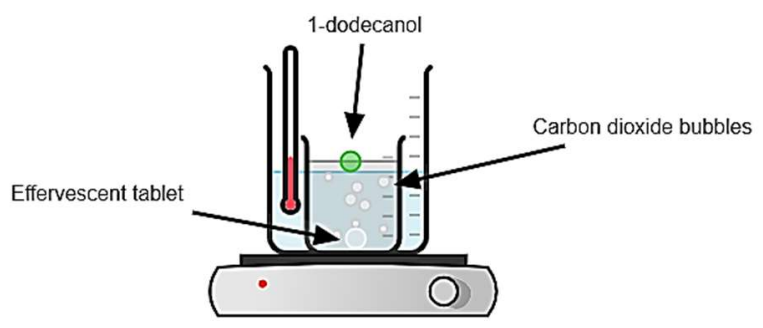

Figure 3. Graphical illustration of the extraction procedure

Then, the solution was vortexed for $5 \mathrm{~min}$ before the separated organic phase was collected by a pipette, filtered ( $0.45 \mu \mathrm{m}$ cellulose membrane filter), and dissolved in $1 \mathrm{~mL}$ of methanol before injected into the LC system for final determination. No adjustment on solution $\mathrm{pH}$ and addition of salt was made as the mechanism was based on the acidbase reaction. Thus, acid neutralised carbonate salt, and the reaction was allowed to proceed in a neutral condition. Under an optimum condition, the enrichment factor was calculated using Equation 1:

$$
\mathrm{EF}=\frac{\mathrm{C}_{\mathrm{Org}}}{\mathrm{C}_{\mathrm{aq}}}
$$

where Corg and $\mathrm{C}_{\mathrm{aq}}$ are the concentrations of KET in organic and aqueous phases, respectively.

\section{E. Experimental Design}

In $\mathrm{CCD}, 16$ experiments were conducted randomly to minimise the bias of uncontrolled variables, and the respective design matrix is shown in Table 1 . Three variables, namely volume of extraction solvent $\left(\mathrm{X}_{1}\right)$, number of effervescent tablets $\left(\mathrm{X}_{2}\right)$, and extraction temperature $\left(\mathrm{X}_{3}\right)$, were subjected to optimisation in this study. Satisfaction rotate-ability was set at $\alpha= \pm 1.68$. The peak height was selected as the response (i.e., dependent variable) of the study.

Table 1. Experimental variable and their levels

\begin{tabular}{|l|c|c|c|c|c|}
\hline \multicolumn{1}{|c|}{ Parameter } & $-\boldsymbol{\alpha}$ & $\mathbf{- 1}$ & $\mathbf{0}$ & $\mathbf{+ 1}$ & $+\boldsymbol{\alpha}$ \\
\hline $\begin{array}{l}\text { Effect of extraction } \\
\text { solvent }\left(\mathrm{X}_{1}\right)\end{array}$ & 132 & 200 & 300 & 400 & 468 \\
\hline Effect no. of tablet $\left(\mathrm{X}_{2}\right)$ & 1 & 2 & 3 & 4 & 5 \\
\hline $\begin{array}{l}\text { Effect of temperature } \\
\left(\mathrm{X}_{3}\right)\end{array}$ & 13 & 20 & 30 & 40 & 47 \\
\hline
\end{tabular}

The main effects, interaction effects, and quadratic effects were optimised and evaluated through this design. A $2^{3}$ full factorial design of CCD was generated with STATISTICA version 10 (TIBCO software, Germany). A quadratic model was developed between the dependent and independent variables. The most important effects and variable interactions were assessed following Analysis of Variance (ANOVA). A $p$-value < 0.05 in the ANOVA table indicates the statistical significance of an effect at a 95\% confidence level, including the decision either the model is accepted or rejected. Three-dimensional graphs were used to evaluate the interactive effect of two variables on the response.

\section{F. Method validation}

An analytical figure of merits was evaluated based on linearity, precision, accuracy, the limit of detection, and limit of quantification. A calibration curve was obtained by a series of six standard solutions ranging from 0.01 to $0.50 \mu \mathrm{g} \mathrm{mL} \mathrm{m}^{-1}$. Detection and quantification limits were calculated using the linear regression method. The lowest concentration spiked was $0.01 \mu \mathrm{g} \mathrm{mL}^{-1}$, and triplicate analysis was performed. The extraction recovery was calculated using the following mathematical expression (Equation 2):

$$
\% \mathrm{ER}=\mathrm{EF} \times \frac{\mathrm{v}_{\text {Org }}}{\mathrm{V}_{\mathrm{aq}}} \times 100 \%
$$

where $\mathrm{V}_{\text {Org }}$ and $\mathrm{V}_{\mathrm{aq}}$ are the concentrations of KET in organic and aqueous phases, respectively. 
Concentration levels tested at 0.5, 0.1, and $0.03 \mu \mathrm{gL} \mathrm{mL}^{-1}$, respectively. The precision was evaluated through the repeatability (intra-day), and reproducibility (inter-day) assay of the method with water samples spiked with KET. Both assays were calculated as \%RSD with respect to the measurements made in triplicate $(n=3)$. Concentration levels tested at 0.5 and $0.1 \mu \mathrm{g} \mathrm{mL}{ }^{-1}$, respectively. For real sample analysis, water samples were extracted in the same manner, and the standard addition method was applied.

\section{RESULT AND DISCUSSION}

\section{A. Optimisation of CCD model}

The optimisation plot (Figure 4) shows the predicted conditions for the optimum point and the desirability of the prediction. The second-order polynomial equation obtained for the optimised variables is given by Equation 3:

Peak Height $=8978+598 \mathrm{X}_{1}+768 \mathrm{X}_{2}+66 \mathrm{X}_{3}-967 \mathrm{X}_{1}{ }^{2}-1915 \mathrm{X}_{2}{ }^{2}$ $-3200 \mathrm{X}_{3}^{2}-1238 \mathrm{X}_{1} \mathrm{X}_{2}+1549 \mathrm{X}_{1} \mathrm{X}_{3}-506 \mathrm{X}_{2} \mathrm{X}_{3}$

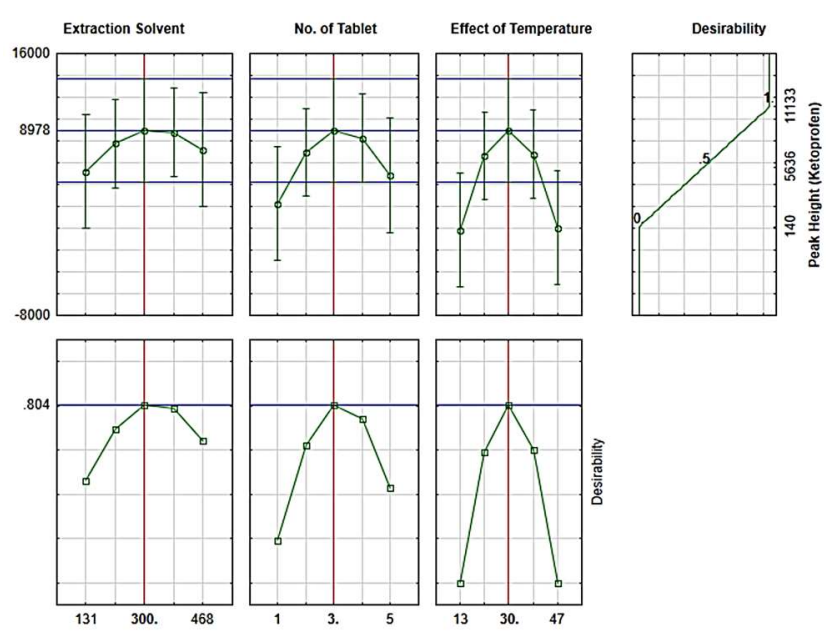

Figure 4. Optimiser plots for studied variables

The positive or negative sign reveals the case when the response (i.e., peak height) is enhanced or reduced, respectively, when passing from the lowest to the highestlevel set for a specific variable (Vidal et al., 2007). For interaction effects, a positive value gives a good sign that the response will increase once both variables change to the same level, such as $\mathrm{X}_{1} \mathrm{X}_{3}$. The ANOVA summary showed that the model was significant, with $p$-value $<0.05$. The $R^{2}$ statistic indicated that the model explained $87 \%$ of the variability. The adjusted $R^{2}$ was calculated at $84 \%$ of the variability. An excellent fitted model should have a minimum $R^{2}$ of $80 \%$ (Joglekar \& May 1987).

In this model, the desirability function of 0.80 was recorded. Desirability function takes values between 0 and 1 , where 0 corresponds to a completely undesirable value and 1 to a completely desirable value (Joglekar \& May 1987). The desirability of 1 was assigned for the maximum response of peak height (11133), 0.5 for the middle (5436), and o for the minimum (140). A lack-of-fit $p$-value of 0.72 implies that it is not significantly associated with the pure error. Thus, the acquired dataset is reliable.

The optimum working condition of extraction procedures as suggested by the model is $300 \mu \mathrm{L}$ 1-dodecanol, 3 pieces of tablets, and $30^{\circ} \mathrm{C}$ extraction temperature. A $p$-value < 0.05 signifies the statistical significance of an effect at a 95\% confidence level (Table 2). The enrichment factors were recorded at 89 . Good enrichments are needed to increase the high probability of extraction, especially when dealing with a low-level concentration of pollutant like KET.

Table 2. Analysis of variance (ANOVA) for the second-order regression model

\begin{tabular}{|c|c|c|c|c|c|}
\hline Factor & SS & Df & MS & F & P \\
\hline $\begin{array}{c}\text { (1) Extraction } \\
\text { Solvent (L) }\end{array}$ & 489346 & 1 & 489346 & 0.652 & 0.450 \\
\hline $\begin{array}{c}\text { Extraction } \\
\text { Solvent (Q) }\end{array}$ & 883844 & 1 & 883844 & 1.178 & 0.319 \\
\hline $\begin{array}{c}\text { (2) No. of Tablet } \\
\text { (L) }\end{array}$ & 807001 & 1 & 807001 & 1.076 & 0.339 \\
\hline $\begin{array}{c}\text { No. of Tablet (Q) } \\
\text { (3) Effect of } \\
\text { Temperature (L) }\end{array}$ & 3399552 & 1 & 3399552 & 4.533 & 0.047 \\
\hline $\begin{array}{c}\text { Effect of } \\
\text { Temperature (Q) }\end{array}$ & 9491115 & 1 & 9491115 & 12.657 & 0.011 \\
\hline 1L by 2L & 1226115 & 1 & 1226115 & 1.635 & 0.248 \\
\hline 1L by 3L & 1919520 & 1 & 1919520 & 2.559 & 0.160 \\
\hline 2L by 3L & 205436 & 1 & 205436 & 0.273 & 0.619 \\
\hline Error & 4499074 & 6 & 749845 & & 0.931 \\
\hline Total SS & 19365653 & 15 & & & \\
\hline
\end{tabular}

The normality assumption was satisfied as to the residuals in the plot distributed along a straight line (Figure 5). The errors were normally distributed, and there were no critical violations of the assumptions that underlay the analysis. This latent information will ensure that the model provides an adequate approximation to the optimisation process (Khodadoust et al., 2013). 


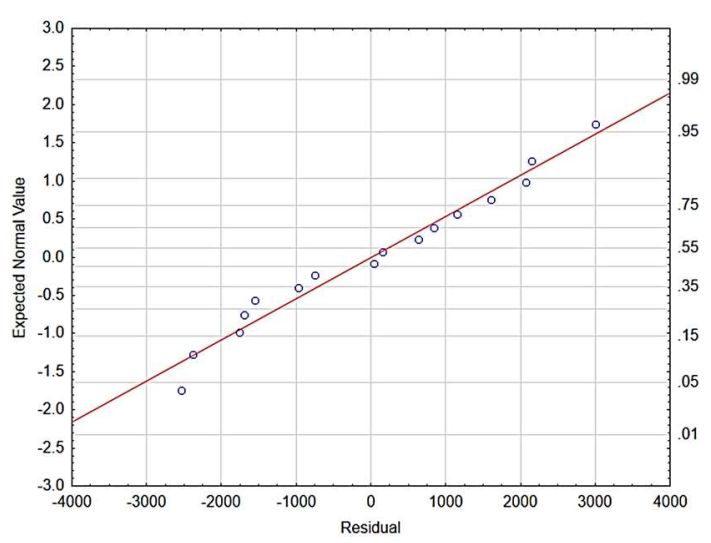

Figure 5. Normal probability plot

\section{B. Effect Volume of Solvent Extraction}

The effect of the volume of 1-dodecanol (extracting solvent) on the extraction efficiency was investigated. An ideal volume required is important to determine if KET is effectively extracted in the organic phase. The results illustrated in Figure 6 show that by increasing the volume of 1-dodecanol, the peak height response increased and reached $300 \mu \mathrm{L}$. For the remaining volume, the response remained constant or insignificantly different. The 1-dodecanol (log kow 5.13) becomes a good extractant as the solvent fulfils several requirements, such as immiscible with water, capable of dissolving analyte in water, low volatility, low density (o.830 $\mathrm{mg} \mathrm{L}^{-1}$ ), and low melting point below room temperature (Przyjazny, 2019). 1-dodecanol is a good extraction solvent owing to its hydrophobic end and hydroxyl group that can extract target analytes by hydrophobic or hydrogen bond effect (Hu et al., 2017).

Similar to other non-steroidal anti-inflammatory drugs (NSAIDs), KET has high $\log \mathrm{P}=3.12$, which implies that the compound is preferred in an organic phase. The contribution of 1-docecanol to extract KET in the CCD model reached $36.09 \%$. The elliptical contour plot designated a significant interaction between extraction solvent volume and number of tablets on the effectiveness of KET extraction. When a low volume of 1-dodecanol and a small number of tablets were introduced into water samples, the extraction efficiency was low. This may be attributed to the facts that when a low amount of 1-dodecanol was used, the effective surface areas for adsorption process reduced and the acceleration of dispersion phenomena decreased due to insufficient tablets (Khodadoust et al., 2013).
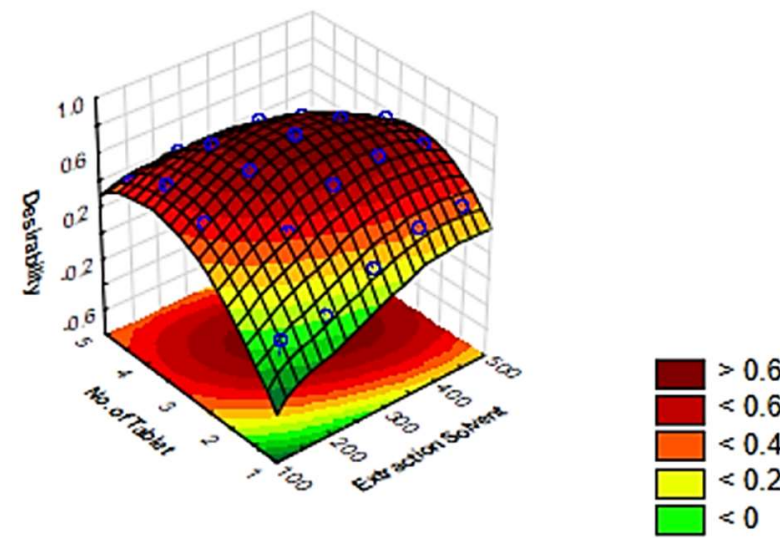

Figure 6. 3D response of interaction term between no. of tablet $v$ s extraction solvent

\section{Effect Number of Tablets}

Adding a high number of effervescent tablets to an aqueous sample can produce more bubbles and accelerate the dispersion of the extraction solvent but simultaneously induce the increment of ionic strength and viscous resistance effect (Li et al., 2019). In this work, 3 tablets were sufficient to assist 1-dodecanol for extracting KET in the aqueous phase. The formation of $\mathrm{CO}_{2}$ bubbles was a quick process, and the probability of bicarbonate ions to come in contact with hydrogen ions was affected by temperature. The higher the temperature, the faster the molecules moved to the top of the aqueous solution, which led to the enrichment of KET by 1dodecanol. The role of the tablets in enhancing the peak height response contributed up to $59.52 \%$ (Figure 7 ). Thus, it gave a good sign that the effectiveness of analyte transfer highly depends on the formation of $\mathrm{CO}_{2}$ bubbles, which were generated in the condition without external energy.

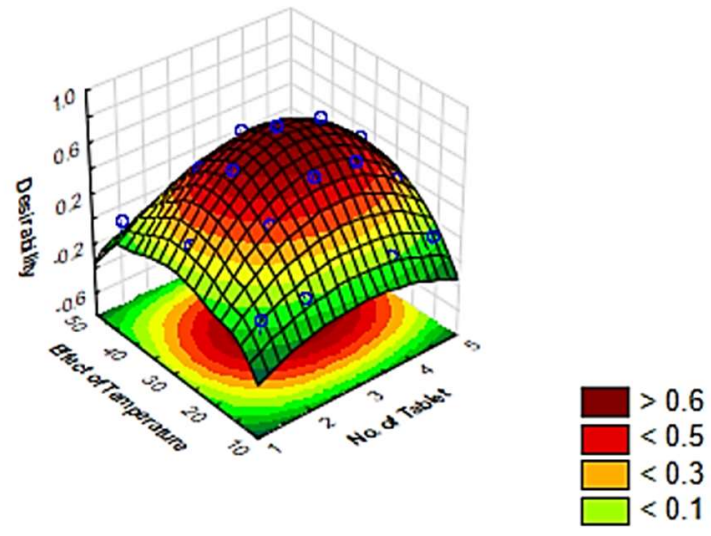

Figure 7.3D response of interaction term between the effect of temperature $v s$ no. of tablet 


\section{Effect of Temperature Change}

Temperature affects the mass transfer process and thus influences extraction efficiency. The influence of extraction temperature was investigated in the range of $13-47^{\circ} \mathrm{C}$. This range included the melting point of 1 -dodecanol at $24^{\circ} \mathrm{C}$. The response of peak height showed an increment from 13 to $30^{\circ} \mathrm{C}$ but decreased significantly afterwards. At low temperature, 1dodecanol tends to remain in solid form, thus making extraction inefficient because the dissolution of tablets is still incomplete. The contour line appeared in a circular pattern, which indicated sensitive interaction effects between the number of tablets and temperature change at a narrow scale. Thus, at a suitable condition, the adjustment of temperature has a synergistic effect towards solvent extraction, by considering $57.28 \%$ contribution of the interaction of $\mathrm{X}_{1} \mathrm{X}_{3}$ (Figure 8).

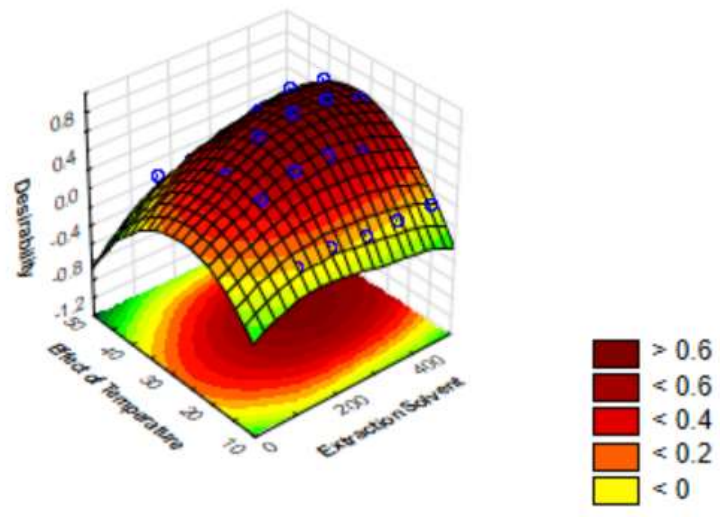

Figure 8. 3D response of interaction term between the effect of temperature $v$ s extraction solvent

\section{E. Analytical Figure or Merits}

A good linearity range was achieved at a satisfactory level of $R^{2}>$ 0.990. The sensitivity of the developed method was shown by calculating the limit of detection and quantification (LOD and LOQ), which were recorded at 0.001 and $0.004 \mu \mathrm{g}$ $\mathrm{mL}^{-1}$, respectively. Good extraction recovery of $85 \%-108 \%$ was recorded when three concentrations of spiked KET (0.5, 0.1 , and $0.03 \mu \mathrm{gLL}^{-1}$ ) were introduced into matrix samples. The repeatability test indicated low bias measurement (i.e., < 10 RSD), which was below the acceptable value proposed by AOAC guidelines.
Table 3. Analytical performance of the extraction method for determination ketoprofen in water samples

\begin{tabular}{|c|c|}
\hline Merit & Ketoprofen \\
\hline Linearity, $\mathrm{r}^{2}$ & $0.990\left(\right.$ range $\left.0.01-0.50 \mu \mathrm{gL}^{-1}\right)$ \\
\hline LOD & $0.001 \mu \mathrm{g} \mathrm{mL}^{-1}$ \\
\hline LOQ & $0.004 \mu \mathrm{g} \mathrm{mL}^{-1}$ \\
\hline ER & $85-108 \%$ \\
\hline RSD (Intra-day), $\mathrm{n}=3$ & $0.05 \mu \mathrm{g} \mathrm{mL}^{-1}(8) ; 0.01 \mu \mathrm{g} \mathrm{mL}^{-1}(10)$ \\
\hline RSD (Inter-day), $\mathrm{n}=3$ & $0.05 \mu \mathrm{g} \mathrm{mL}^{-1}(1) ; 0.01 \mu \mathrm{g} \mathrm{mL}^{-1}(10)$ \\
\hline Real sample & $\begin{array}{l}\text { 0.059 } \mu \mathrm{g} \mathrm{mL}^{-1} \text { (KET gel, o.075 } \mu \mathrm{g} \mathrm{mL}^{-} \\
\left.{ }^{1}\right) ; 4.49 \mu \mathrm{gL}^{-1} \text { (standard solution, } 5 \mu \mathrm{g} \\
\mathrm{mL}^{-1} \text { ) }\end{array}$ \\
\hline
\end{tabular}

To evaluate the efficiency of the proposed method, tap water samples were fortified with KET gel, and standard solutions were studied. The results showed acceptable extraction recoveries for the spiked samples, calculated at $0.059 \mu \mathrm{gL}^{-1}$ (KET gel, $0.075 \mu \mathrm{g} \mathrm{mL}^{-1}$ ) and $4.49 \mu \mathrm{g} \mathrm{mL}^{-1}$ (standard solution, $5 \mu \mathrm{g} \mathrm{mL}^{-1}$ ), respectively (Table 3 ). Chromatographic detection of spiked standard solution and KET gel, as shown in Figure 9.
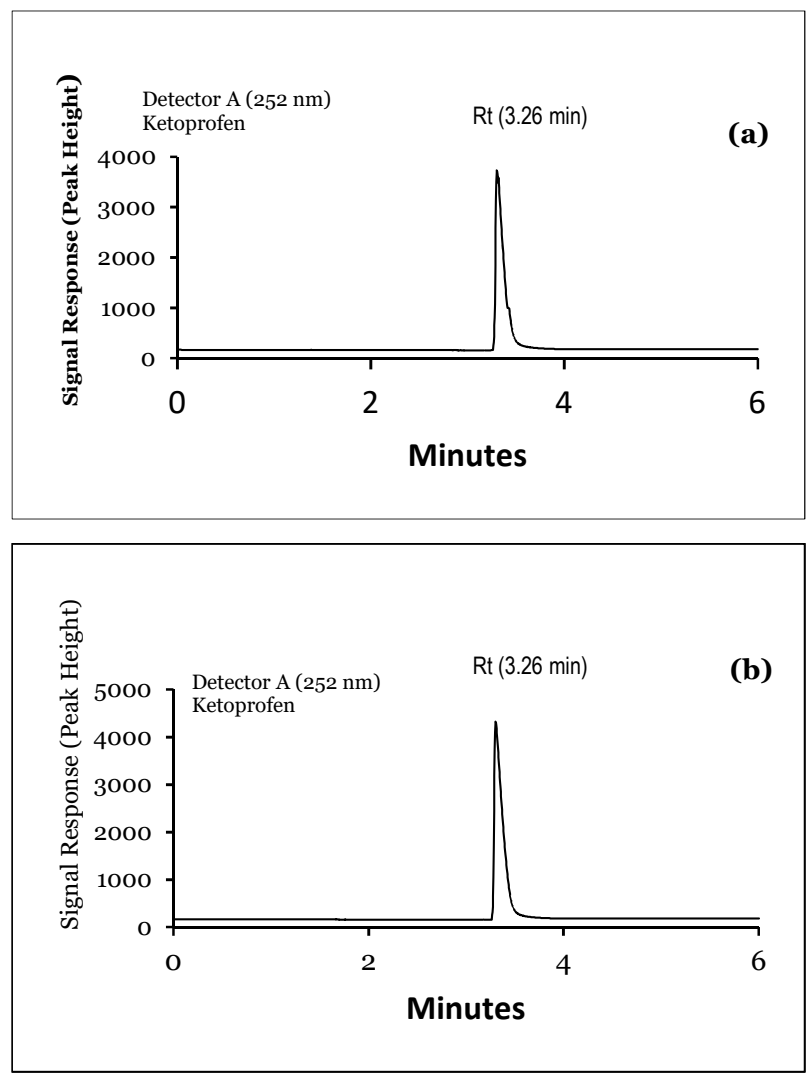

Figure 9. Chromatograms of KET detection in (a) standard solution, $0.01 \mu \mathrm{g} \mathrm{mL}^{-1}$ and (b) spiked solution contain KET gel 


\section{F. Comparison with other Methods}

No similar analytical techniques to determine KET in water samples using effervescent-assisted microextraction were found in the literature. Thus, a comparison with the analytical figure of merits is subjected to other extraction techniques, which have been reported previously by researchers. The developed method shows comparable performance in terms of recovery assay. Thus, it is proven that the replacement of the halogenated solvent with 1dodecanol does not detriment method capability. The application of effervescent tablets indirectly leads to the elimination of energy dependence on the acceleration of fine dispersion. Limit of detection may reach lower value if determined using sophisticated methods, such as liquid chromatography (LC-MS) that reflects the sensitivity levels of the instrument itself. Nonetheless, the enrichment factor calculated in this work reported higher than literature studies, EF < 12 (Park \& Myung 2015). A comparison of the represented method with other approaches reported in the literature for the extraction of KET in water samples is given in Table 4.

Table 4. Comparison of method performance with other extraction techniques

\begin{tabular}{|l|l|l|l|}
\hline \multicolumn{1}{|c|}{ Method } & Instrument & \multicolumn{1}{|c|}{$\begin{array}{c}\text { LOD } \\
\left(\boldsymbol{\mu g} \mathbf{L}^{-1}\right)\end{array}$} & \\
\hline SPE $^{\mathrm{a}}$ & HPLC-PDA & 0.08 & $83-102$ \\
\hline SPME $^{\mathrm{b}}$ & LC-DAD & 2.2 & - \\
\hline DLLMME $^{\mathrm{c}}$ & UHPLC-DAD & 0.5 & $89.1-132$ \\
\hline DLLME $^{\mathrm{d}}$ & LC-MS-DAD & 0.88 & $98-102$ \\
\hline DLLME & LC-MS & 0.0003 & 76 \\
\hline This work & HPLC-UV & 1.0 & $85-102$ \\
\hline
\end{tabular}

a Madikizela et al. 2014, b Vera-Candioti et al. 2008, c Montesdeoca-Esponda et al. 2008, d Park \& Myung 2015, e Zgoła-Grzeskowiak et al. 2011

\section{CONCLUSION}

The research work illustrated the successful application of the dispersive liquid-liquid microextraction combined with the effervescent tablet as a dispersive agent. The chemometric approach, namely $2^{3}$ central composite design, was operated to find the optimal condition for microextraction. The statistical model and 3D response surfaces showed detail effect of factors on each variable and also on the extraction efficiency in combination mode. The optimised method shows good performance to extract KET drug in water samples at low-level concentration. Low bias values obtained in calculated data explain that the method seems suitable to use for routine analysis. In addition, the developed method may be utilised for the determination of other NSAID drugs to strengthen the effectiveness in future work.

\section{ACKNOWLEDGEMENTS}

The authors acknowledge the Ministry of Education Malaysia and Universiti Malaysia Terengganu for providing financial support under the research grant FRGS/1/2019/STGo1/ UMT/o3/3 (Vot 59585).

\section{REFERENCES}

Hatami, M, \& Farhadi, K 2013, 'Analysis of ketoprofen enantiomers in human and rat plasma by hollow-fiberbased liquid-phase microextraction and chiral mobilephase additive HPLC', Canadian Journal of Chemistry, vol. 91, pp. 1252-1257.

Hu, S, Yang, X, Xue, J, Chen, X, Bai, XH \& Yu, ZH 2017 , 'Graphene/dodecanol floating solidification microextraction for the preconcentration of trace levels of cinnamic acid derivatives in traditional Chinese medicines', Journal of Separation Science, vol. 40, pp. 2959-2966.

Jiang, W, Chen, X, Liu, F, You, X \& Xue, J 2014, 'Effervescence-assisted dispersive liquid-liquid microextraction using a solid effervescent agent as a novel dispersion technique for the analysis of fungicides in apple juice', Journal of Separation Science, vol. 37, pp. 31573163 . 
Joglekar, AM \& May, AT 1987, 'Product excellence through design of experiments', Cereal Foods World, vol. 32, pp. 857.

Kermia, AEB, Fouial-Djebbar, D \& Trari, M 2016, 'Occurrence, fate and removal efficiencies of pharmaceuticals in wastewater treatment plants (WWTPs) discharging in the coastal environment of Algiers', Comptes Rendus Chimie, vol. 19, 963-970.

Khodadoust, S, Ghaedi, M \& Hadjmohammadi, MR 2013, 'Dispersive nano solid material-ultrasound assisted microextraction as a novel method for extraction and determination of bendiocarb and promecarb: response surface methodology', Talanta, vol. 116, pp. 637-646.

Leong, MI, Fuh, MR \& Huang, SD 2014, 'Beyond dispersive liquid-liquid microextraction', Journal of Chromatography A, vol. 1335, pp. 2-14.

Li, Y, Hu, J, Liu, W, Jin, L, Zhou, P, Zhang, Y \& Zhou, Y 2019, Magnetic effervescent tablet-assisted ionic liquid-based dispersive liquid-liquid microextraction of polybrominated diphenyl ethers in liquid matrix samples', Talanta, vol. 195, pp. 785-795.

Liu, X, Shen, Z, Wang, P, Liu, C, Zhou, Z \& Liu, D 2014, 'Effervescence assisted on-site liquid phase microextraction for the determination of five triazine herbicides in water', Journal of Chromatography A, vol. 1371, pp. 58-64.

Madikizela, LM, Muthwa, SF \& Chimuka, L 2014, 'Determination of triclosan and ketoprofen in river water and wastewater by solid phase extraction and high performance liquid chromatography', South African Journal of Chemistry, vol. 67, pp. 143-150.

Montesdeoca-Esponda, S, Mahugo-Santana, C, Sosa-Ferrera, Z \& Santana-Rodríguez, JJ 2015, 'A dispersive liquid-liquid micellar microextraction for the determination of pharmaceutical compounds in wastewaters using ultrahigh performace liquid chromatography with DAD detection. Biomedical Chromatography, vol. 29, pp. 353356.

Park, SY \& Myung, SW 2015, 'Simultaneous determination of non-steroidal anti-inflammatory drugs in aqueous samples using dispersive liquid-liquid microextraction and HPLC analysis', Bulletin of the Korean Chemical Society, vol. 36, pp. 2901-2906.

Przyjazny, A 2019, 'Extraction: liquid-phase microextraction', Elsevier, vol. 2019, pp. 52-62.

Rezaee, M, Assadi, Y, Hosseini, MRM, Aghaee, E, Ahmadi, F \& Berijani, S 2006, 'Determination of organic compounds in water using dispersive liquid-liquid microextraction', Journal of Chromatography A, vol. 1116, pp. 1-9.

Vera-Candioti, L, García, MG, Galera, MM \& Goicoechea, HC 2008, 'Chemometric assisted solid-phase microextraction for the determination of anti-inflammatory and antiepileptic drugs in river water by liquid chromatography-diode array detection', Journal of Chromatography A, vol. 1211, pp. 22-32.

Vidal, L, Chisvert, A, Canals, A \& Salvador, A 2007, 'Sensitive determination of free benzophenone-3 in human urine samples based on an ionic liquid as extractant phase in single-drop microextraction prior to liquid chromatography analysis', Journal of Chromatography A, vol. 1174, pp. 95-103.

Xiao-Huan, Z, Qiu-Hua, WU, Zhang, MY, Guo-Hong, XI \& Zhi, W 2009, 'Developments of dispersive liquid-liquid microextraction technique', Chinese Journal of Analytical Chemistry, vol. 37, pp. 161-168.

Yıldız, E \& Çabuk, H 2018, 'A new solidified effervescent tablet-assisted dispersive liquid-liquid microextraction for the analysis of fungicides in fruit juice samples', Analytical methods, vol. 10, pp. 330-337.

Zgoła-Grześkowiak, A \& Grześkowiak, T 2011, 'Dispersive liquid-liquid microextraction', TrAC Trends in Analytical Chemistry, vol. 30, pp. 1382-1399. 